\title{
CIRCULATORY EFFECTS OF RAISED AIRWAY PRESSURE DURING CYCLOPROPANE ANESTHESIA IN MAN ${ }^{1}$
}

\author{
BY HENRY L. PRICE, BENTON D. KING, JOHN D. ELDER, BENJAMIN H. \\ LIBIEN, AND ROBERT D. DRIPPS \\ (From the Department of Anesthesiology, Hospital of the University of Pennsylvania, the \\ Harrison Department of Surgical Research, University of Pennsylvania School of \\ Medicine and the Department of Anesthesiology, Philadelphia \\ General Hospital, Philadelphia, Pa.)
}

(Submitted for publication June 25, 1951 ; accepted August 13, 1951)

Although the effects of increased intrapulmonary pressure on the circulation in normal, conscious man have been carefully studied (1-7), knowledge of the changes resulting from raised airway pressure in anesthetized man is virtually lacking. Since positive pressure inflation of the lungs is commonly used to secure adequate ventilation in anesthetized patients, this information should be available.

It is generally agreed (3-7) that the most striking circulatory effect of positive pulmonary pressure, either intermittent or continuous, in normal conscious individuals, is a reduction of cardiac output. In some subjects cardiac output may be maintained during pressure breathing (7), but the stroke volume of the heart is low, and its output is maintained because of a marked rise in the pulse rate. The reduction of stroke volume is presumed to result (4) from a diminished filling of the right ventricle, caused by the rise in intrathoracic pressure occurring when the lungs are inflated under positive pressure. In response to these changes, a vasoconstriction occurs $(2,8-10)$ which tends to reduce peripheral pooling of blood and improves the return of blood to the heart.

In animals studied under general anesthesia, the arterial pressure declined more in response to raised airway pressure when anesthesia was profound than when it was less deep (11). It has been assumed that the same would be true in man (12).

It was therefore surprising to us to note that although maintained positive pressure in the respiratory tract caused a considerable lowering of blood pressure in conscious and in lightly-anes-

1 This investigation was supported (in part) by a research grant from The National Heart Institute, Public Health Service. thetized patients, it caused much less decrease or no decrease at all in more deeply anesthetized patients. It is with these observations, as they relate to cyclopropane anesthesia, that the present report deals.

\section{METHODS}

A. Subjects. Twelve hospital patients aged 16 to 62 were studied. All were to undergo operation following anesthetization with cyclopropane, and all had received pre-anesthetic medication one hour before the studies began. This consisted of 8-16 mgm. morphine sulfate and 0.4-0.6 mgm. atropine sulfate or scopolamine hydrobromide. No signs or symptoms of cardiovascular or respiratory disease were present in any case. The arterial pressure of all subjects was normal when measured the day preceding operation, with the exception of numbers 9 and 11, who had resting arterial pressures of 130/90 and $140 / 85$, respectively. The effects of raised airway pressure were observed while the subject was conscious, following which anesthesia was induced. Sodium thiopental (200-250 mgm.) was used for induction in three cases (Cases 2, 4, 6) and small quantities of diethyl ether were employed together with cyclopropane in three instances (Cases $1,2,11$ ). In all cases the depth of anesthesia was increased rapidly with cyclopropane, a cuffed endotracheal tube was introduced into the trachea under direct vision, the cuff inflated, and the airway pressure raised for the second time. Following this, the patients breathed pure oxygen for several minutes; then the airway pressure was increased again. Arterial blood was obtained from four patients (Cases 4, 10, 11, 12) under "deep" cyclopropane anesthesia, and an average value of $21 \mathrm{mgm}$. per cent was obtained by the method of Orcutt and Waters (13).

B. Respiratory tract pressure apparatus. Pressure was applied to the airway for periods ranging from 20 to 80 seconds through a Bennett research model face mask or through a direct connection to the endotracheal tube. The pressure apparatus delivered 100 per cent oxygen through wide-bore tubing from a 200 liter reservoir. The reservoir was supplied with gas delivered from a standard $G$ cylinder by a demand reducing valve (Mine Safety Appliances Co., for Pneophore) set to maintain the desired pressure. Additional wide-bore tubing led 
to a large variable-pressure water-trap outflow. Since gas under pressure was necessary to supply the apparatus, the choice of gases rested between compressed air and oxygen. The latter was chosen because it approximated the oxygen content of the anesthetic mixture more closely than did room air. Preliminary studies indicated that the apparatus could inflate the lungs at the pre-set pressure within 2-3 seconds, and maintain constant pressure within $\pm 2 \mathrm{~cm} . \mathrm{H}_{2} \mathrm{O}$ during normal respiration. All anesthetized individuals became apneic as soon as pressure was applied to the airway, or were apneic as the result of anesthesia alone. Some conscious subjects were instructed to hold the breath in inspiration in order to make the effects of raised airway pressure as similar as possible to those produced during anesthesia. However, several subjects had difficulty in keeping the glottis open during the period of raised airway pressure under these conditions. Pressures from 22 to $25 \mathrm{~cm}$. $\mathrm{H}_{2} \mathrm{O}$ were applied to the airway of the first patients studied. Later it became important to know how much airway pressure was necessary to cause a reduction of the arterial pressure of anesthetized patients. For this purpose, airway pressure was raised by $5 \mathrm{~cm} . \mathrm{H}_{2} \mathrm{O}$ increments over the range from 10 to $30 \mathrm{~cm} . \mathrm{H}_{2} \mathrm{O}$.

C. Pressure measurements. Lilly capacitance manometers were used to measure arterial and venous pressures, and the outputs were led to a double-channel Brush inkwriter. The manometers were calibrated against aneroid and water manometers several times during the course of each study, and against atmospheric pressure before and after each reading. The aneroid manometer was checked for accuracy against a mercury manometer. Pressures were recorded from the brachial artery in each case by means of short plastic catheters (14). Antecubital venous pressure was measured in three cases from similar catheters. In the remaining nine cases long radiopaque catheters were introduced through antecubital veins into the right atrium (four cases), the superior vena cava (one case), the innominate vein (three cases), and the internal jugular vein (one case). The location of the catheters was determined from X-rays taken at the end of the study. The reference level for venous pressures was the plane $5 \mathrm{~cm}$. dorsal to the 4th costochondral junction. Mean pressures were obtained either by electrical damping or visually. The two values agreed within the limits of accuracy $\left( \pm 0.2 \mathrm{~cm} . \mathrm{H}_{2} \mathrm{O}\right)$ of the method employed.

Raised airway pressure produced an increase in venous pressure. This increment was believed to measure the increase in intrapleural pressure immediately adjacent to the heart and great veins which resulted from inflation of the lungs. The accuracy of this measurement in man has not been evaluated. In animals, the increment of peripheral venous or right atrial pressure produced by inflation of the lung under positive pressure varies linearly with intrapleural pressure over the range of airway pressures employed in the present study $(1,15)$.

\section{RESULTS}

\section{A. Effect of Cyclopropane Anesthesia on Arterial Pressure, Heart Rate, and Venous Pressure}

There was no consistent effect of cyclopropane anesthesia on the arterial pressure or heart rate of the 12 patients. Probably because of anxiety, the arterial pressure and pulse rate of most of the subjects were above normal prior to induction of anesthesia. In five cases arterial pressure tended to return toward normal values as anesthesia was deepened. Seven patients, however, became more hypertensive during anesthesia. Four patients exhibited bradycardia (range 46 to 58 beats per minute) and two developed tachycardia (110 to 130 beats per minute) as anesthesia was deepened.

In contrast to this variability, intrathoracic venous or right atrial pressure increased consistently during anesthesia. The mean maximal rise of pressure in or near the right atrium of the nine subjects in whom such measurements were made was $12.5 \mathrm{~cm} . \mathrm{H}_{2} \mathrm{O}$ above the level noted prior to anesthesia. The range was from 8 to $21 \mathrm{~cm} . \mathrm{H}_{2} \mathrm{O}$. Less of a rise was recorded during less profound anesthesia, the mean rise being $6.6 \mathrm{~cm} . \mathrm{H}_{2} \mathrm{O}$, with a range from 2.5 to $11 \mathrm{~cm} . \mathrm{H}_{2} \mathrm{O}$, in those patients referred to subsequently as "lightly anesthetized."

\section{B. The Effect of Raised Airway Pressure on Ar- terial and Venous Pressures}

1. Arterial. Table I lists the effect of 22-25 $\mathrm{cm} . \mathrm{H}_{2} \mathrm{O}$ airway pressure on the arterial pressure of nine subjects. Averages of these values are plotted in Figure 1, which illustrates a five-phase response for conscious individuals. This consisted of (1) a sharp, small rise in systolic, diastolic, and pulse pressure lasting 1-2 seconds, (2) a decrease in all three pressures which became maximal within 6-10 seconds, and was followed by (3) a slow return toward control values. With the release of airway pressure there was (4) a sharp, slight decrease in all values, followed by (5) an "overshoot" which reached a maximum within four to seven seconds.

In ightly anesthetized subjects there was no tendency for arterial pressure to return toward control values while airway pressure was elevated. "Overshoot" was absent in five cases and minimal 
TABLE I

Effect of raised airway pressure on arterial and venous pressures of nine subjects

A. Subjects conscious. B. Subjects lightly anesthetized. C. Subjects deeply anesthetized.

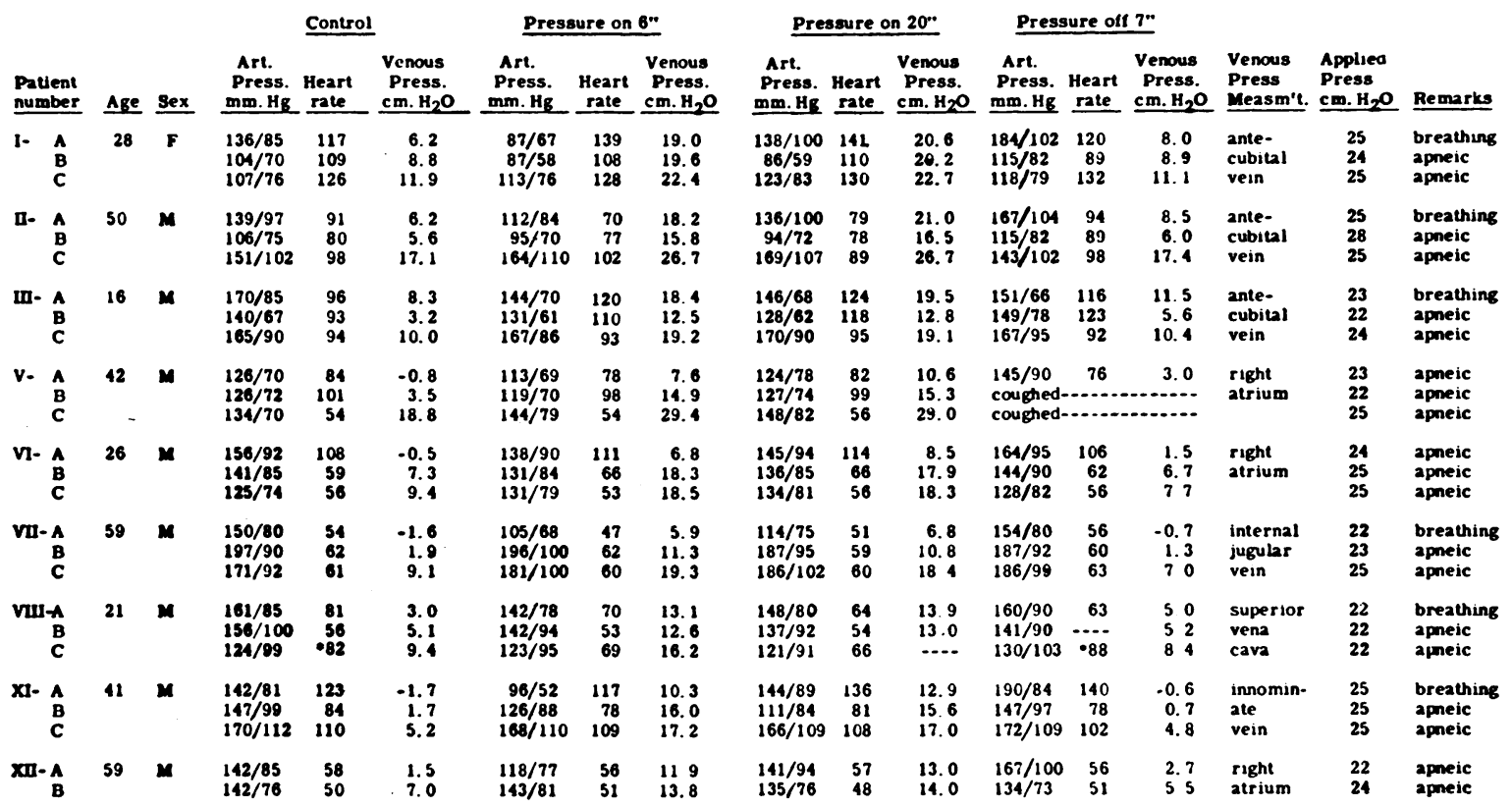

* Pulsus alternans

in four. "Overshoot" was considered absent if the systolic pressure did not exceed control values within eight seconds after the release of airway pressure. During deep anesthesia there was no depression of pulse pressure during raised airway pressure in any subject. In two cases (Nos. 8, 11) systolic and diastolic pressures decreased slightly. Again "overshoot" was absent. After release of airway pressure, diastolic and pulse pressure rose sluggishly to levels above the control values, but this response required 25 to 60 seconds to become maximal.

The lowest level of systolic, diastolic and pulse pressure in response to raised airway pressure was compared to the control value for conscious, lightly and deeply anesthetized subjects. The results appear in Table II.

The response of the systolic, diastolic and pulse pressures to raised airway pressure in conscious subjects was significantly different from that which occurred when the same individuals were deeply anesthetized $(p<0.01)$. Reduction of systolic and pulse pressures was significantly greater when subjects were lightly anesthetized than when anesthesia was profound $(p<0.01)$, and the change in diastolic pressure was significantly different $(p<0.05)$. The reductions in systolic, diastolic, and pulse pressure were all significantly greater when the subjects were conscious than during light anesthesia $(\mathrm{p}<0.05)$.

2. Venous pressure. The venous pressure responses of the nine subjects to raised airway pressure are listed in Table $I$. The venous pressure measurements recorded during the five phases of arterial pressure response referred to previously were averaged and plotted in Figure 1. Venous pressure rose abruptly as increased pressure was applied to the airways of conscious, lightly or deeply anesthetized subjects. As raised airway pressure was maintained, venous pressure continued to rise slowly in the conscious subjects (arterial pressure tending to return toward control values : phase 3 ). In lightly anesthetized subjects, venous pressure rose slightly or not at all during the same period (arterial pressure showing no tendency to return toward control values). In deeply anesthetized subjects, venous pressure did not rise or decreased slightly at this time (arterial pressure essentially same as in control period). 


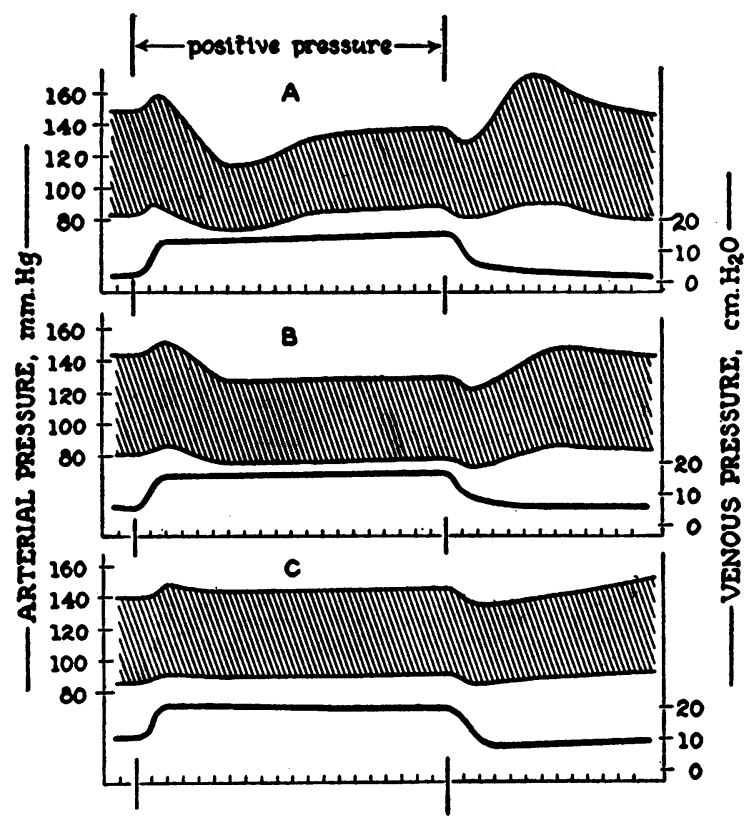

Fig. 1. Effect of Raised Airway Pressure on Arterial and Venous Pressures of Nine Subjects

A. Subjects conscious. B. Subjects lightly anesthetized. C. Subjects deeply anesthetized.

A further difference in the venous pressure response among the three groups was noted as airway pressure was released. In conscious subjects venous pressure was $1.9 \pm 0.25$ (S.E.) $\mathrm{cm}$. $\mathrm{H}_{2} \mathrm{O}$ above the control value at six seconds-the time of the maximal "overshoot" of arterial pressure. At this time in the lightly anesthetized subjects venous pressure was $0.21 \pm 0.38$ (S.E.) cm. $\mathrm{H}_{2} \mathrm{O}$ above control values and there was little or no "overshoot" of arterial pressure. In deeply anesthetized subjects, venous pressure at this period was less than the control value by $1.3 \pm$ 0.34 (S.E.) $\mathrm{cm} . \mathrm{H}_{2} \mathrm{O}$ and arterial pressure was either the same or slightly lower than control values. Each of these values is significantly different from either of the other two $(p<0.01)$.

From the foregoing it is apparent that there was a relationship between the response of ve- nous pressure and arterial pressure when airway pressure was raised.

\section{The Relationship Between the Arterial Pres- sure and the Forces Acting on the Intra- thoracic Veins and Right Atrium}

Increased pressure in the airway caused a rise in venous pressure in the nine subjects referred to in Section 2. In conscious subjects airway pressures of $22-25 \mathrm{~cm} . \mathrm{H}_{2} \mathrm{O}$ resulted in increases in venous pressure of $11-15 \mathrm{~cm} . \mathrm{H}_{2} \mathrm{O}$, a "transmission" of $55 \pm 1.4$ (S.E.) per cent. Anesthesia apparently affected the "transmission," since the same increase in airway pressure resulted in a 10 $13 \mathrm{~cm} . \mathrm{H}_{2} \mathrm{O}$ rise in venous pressure during light anesthesia ( $45 \pm 0.8$ [S.E.] per cent), and only 9-11 cm. $\mathrm{H}_{2} \mathrm{O}$ during deep anesthesia $(41 \pm 1.6$ [S.E.] per cent). Each of these values is significantly different from either of the others, with $\mathrm{p}<0.01$ for conscious compared to anesthetized subjects, and $\mathrm{p}<0.05$, comparing light and deep anesthesia. It is apparent that the three episodes of raised airway pressure were not comparable so far as the circulatory effects were concerned.

Cyclopropane anesthesia, therefore, not only increased the pressure in the intrathoracic veins and right atrium, but at the same time diminished the "transmission" of raised airway pressure to these structures.

Four subjects were exposed, during cyclopropane anesthesia, to gradually increasing airway pressure until arterial pressure began to decrease (see Methods). Arterial and pulse pressures were maintained during raised airway pressure so long as the rise in central venous pressure produced by anesthesia exceeded the venous pressure increment, or "transmission" of pressure to the heart and great veins. This relationship was independent of the "depth" of anesthesia.

Re-examination of the data obtained in the patients subjected to $22-25 \mathrm{~cm} . \mathrm{H}_{2} \mathrm{O}$ airway pressure showed that the same relationship held be-

TABLE II

\begin{tabular}{l|c|c|c}
\hline \hline & Syst. press. & Diast. press. & Pulse press. \\
\hline & $(m m . H g)$ & $(m m . H g)$ & $(m m . H g)$ \\
Conscious & $-31.1 \pm 4.8$ (S. E.) & $-13.9 \pm 2.9$ (S. E.) & $-17.4 \pm 2.8$ (S. E.) \\
Light anesthesia & $-16.2 \pm 3.4$ (S. E.) & $-6.1 \pm 2.6$ (S. E.) & $-10.1 \pm 1.3$ (S. E.) \\
Deep anesthesia & $+4.6 \pm 1.4$ (S. E.) & $+2.1 \pm 2.4$ (S. E.) & $+2.5 \pm 1.4$ (S. E.) \\
\hline
\end{tabular}


tween "transmitted" pressure, intrathoracic venous pressure and arterial pressure. In other words, in all patients in whom there was no reduction of arterial pressure in response to raised airway pressure, the rise in intrathoracic venous or right atrial pressure associated with anesthesia was greater than the pressure transmitted to these structures from the airway when the lungs were inflated under positive pressure.

\section{Effect of Increased Respiratory Tract Pres- sure on Heart Rate}

In conscious individuals the effect of raised airway pressure on the heart rate was variable (Table I). Five subjects showed an increased rate, six a slowing, and one no change at the time of the maximal reduction of arterial pressure. As arterial pressure began to return toward control values, the heart rate increased in nine of the 12 cases. When airway pressure was elevated in anesthetized patients the heart rate changed in the same direction in each case as it had during consciousness, but the amount of change was less.

\section{DISCUSSION}

This study was undertaken in an effort to evaluate the effects of anesthesia on the response of the circulation to increased intrapulmonic pressure. It was believed that such information should be made available because positive pressure inflation of the lungs is so commonly used to provide adequate respiratory exchange in anesthetized patients. Inflation of the lungs under constant pressure for periods of 20-60 seconds permitted measurement not only of the amount of arterial pressure reduction produced, but also of the ability of the vascular system to return this pressure toward normal values. The pre-anesthetic medication received by the subjects before study probably affected vasomotor reactivity. However, the differences in the response between conscious and anesthetized subjects may be presumed to result from the action of cyclopropane.

It is believed that phase 1 , the initial rise of systolic, diastolic and pulse pressure in response to raised airway pressure, results both from compression of the thoracic aorta by the expanding lung and from the expulsion of blood from the lung into the left ventricle and systemic circulation
(2). This response was noted in all of the subjects studied whether they were conscious or anesthetized.

Phase 2 differed in conscious, lightly and deeply anesthetized subjects. In conscious individuals arterial pressure decreased, presumably as the result of reduced cardiac output occasioned by a reduction in the degree of filling of the right ventricle $(4,6)$. The reduced filling is explained by the effects of direct mechanical compression of the heart and great veins by the expanded lung (16). Increased pulmonary vascular resistance as the result of raised airway pressure is believed to be of secondary importance (4), and presumably could not limit the output of the heart if the filling of the right ventricle were adequate.

In anesthetized subjects raised airway pressure did not reduce arterial pressure to the same extent as it did when these individuals were conscious. Reduction of arterial pressure varied inversely with the level of intraluminal pressure in the great veins and right atrium, and directly with the amount of pressure transmitted from the airway to these structures. Thus anesthetized subjects were protected against reduction of arterial pressure in two ways: venous pressure was elevated and transmission of airway pressure was reduced.

Whenever right atrial pressure is abnormally high, blood pressure and cardiac output should be better maintained in the face of raised airway pressure. Several investigators have shown this to be the case in patients with elevated venous pressure resulting from congestive heart failure $(17,3-5)$.

The diminished transmission of airway pressure to the intrathoracic viscera observed during anesthesia might result from a diminished tone of the chest wall and diaphragm, but seems as likely to be related to the reduced distensibility of a lung turgid with blood. A decrease in lung distensibility has been observed in patients in congestive heart failure (18).

It is believed that phase 3 , the increase of arterial pressure during maintenance of raised airway pressure is the result of a generalized compensatory vasoconstriction initiated by the decreased arterial pressure noted in phase 2 , and mediated by way of the carotid sinus and aortic arch pressoreceptors and the sympathetic nervous system. In the dog (19), the reflex sympathetic 
activity initiated by elevation of intrapulmonic pressure is greatly reduced by occlusion of the carotid sinuses. In man, blockade of the sympathetic outflow to the lower extremities and splanchnic areas by spinal anesthesia prevented arterial pressure from returning toward normal values while airway pressure was raised (20).

Phase 3 was most evident in the conscious subjects. When the subjects were lightly anesthetized, arterial pressure declined in response to inflation of the lung under positive pressure, but showed little or no tendency to return toward control values while airway pressure was maintained. Peripheral venous, intrathoracic venous, and right atrial pressures did not rise progressively or rose only slightly during this period. It appeared that compensatory vasoconstriction was almost absent. Abramson, Grollman, and Schwartz (21) have concluded, on the basis of plethysmographic studies, that cyclopropane produces great vasodilatation in man, probably both by diminishing the tone of the vasomotor system and by a direct effect upon blood vessels. It is not known which effect is more important in determining the peripheral vascular response under discussion.

Phase 4 , the abrupt decrease in arterial pressure with release of raised airway pressure, occurred in all subjects. It is believed to result from the rapid release of compression of the aorta, coupled with an increased capacity of the lung vessels for blood. The output of the left ventricle is diminished while blood is filling the vessels of the lung.

Phase 5, the "overshoot," was most marked in conscious individuals. It is assumed that this response results from the return to the right ventricle of blood previously pooled in the periphery, and from its subsequent ejection into the constricted vessels of the systemic circulation. It should be recalled that in the conscious subjects peripheral venous, intrathoracic venous and right atrial pressures were elevated at this time. Production of chemical sympathectomy by spinal anesthesia abolished "overshoot" following the release of raised airway pressure in man (20) and in the dog (19). Surgical sympathectomy had the same effect in man (22), as did the administration of tetraethylammonium chloride (20). If the sympathetic vasoconstrictor pathway was "pre-excited," raised airway pressure was not followed by "overshoot" in the dog (19). In two conscious patients of the present series (cases 3 and 8 ), there was no "overshoot" of arterial pressure following the release of raised airway pressure. Both were young, apprehensive individuals who had had normal blood pressures the day prior to study, but whose arterial pressures were $170 / 85$ and $160 / 85$ respectively during the period immediately preceding application of positive pressure. When the subjects were lightly anesthetized, "overshoot" was absent in five and slight in the other four. In only three of the nine patients was venous pressure elevated during this period, and then only slightly. The difference between these responses and those observed in the conscious subjects is a further indication that anesthesia has diminished either the reactivity of the sympathetic nervous system or the ability of the blood vessel wall to contract. Since arterial pressure did not decrease during deep anesthesia in response to raised airway pressure there was no pressoreceptor stimulus.

- Preliminary observations on individuals anesthetized with substances other than cylopropane have shown that the response of the circulation to raised airway pressure is essentially the same as that already described during administration of diethyl ether, but is significantly different during pentothal anesthesia. Further studies of these responses are being carried out.

The cause of the raised venous pressure occurring during cyclopropane anesthesia in man is not known. The increase in right atrial pressure must result initially from a disparity between the amount of blood returning to the heart and the amount ejected from the heart. Measurements of cardiac output, cardiac work and cardiac competence during cyclopropane anesthesia have not been made in man. In the dog the output of the heart is increased (23), the competence of the heart decreased (24), and the right atrial pressure elevated (25) by cyclopropane.

\section{SUMMARY AND CONCLUSIONS}

1. Positive intrapulmonary pressure of 22-25 cm. $\mathrm{H}_{2} \mathrm{O}$ failed to reduce arterial pressure in subjects profoundly anesthetized with cyclopropane. Inflation of the lungs under this pressure reduced arterial pressure slightly when these individuals 
were less profoundly anesthetized and moderately when the subjects were conscious.

2. These differences in arterial pressure response to raised airway pressure appeared to be caused primarily by a pronounced rise in intrathoracic venous and right atrial pressures which occurred during cyclopropane anesthesia. An additional factor responsible for these differences was the diminished "transmission" of airway pressure associated with anesthesia.

3. The behavior of arterial and venous pressures suggested a diminished responsiveness of the peripheral vascular system to lowered arterial pressure in subjects anesthetized with cyclopropane.

\section{REFERENCES}

1. Barach, A. L., Eckman, M., Ginsburg, E., Rumsey, C. C., Jr., Korr, I., Eckman, I., and Besson, G., Studies on positive pressure respiration; general aspects and types of pressure breathing; effects on respiration and circulation at sea level. J. Aviation Med., 1946, 17, 290.

2. Fenn, W. O., Otis, A. B., Rahn, H., Chadwick, L. E., and Hegnauer, A. H., Displacement of blood from the lungs by pressure breathing. Am. J. Physiol., 1947, 151, 258.

3. Chasis, H., Bannon, J. H., Lauson, H. D., Whittenberger, J. L., Galdston, M., and Goldring, W., Final report of contract W-49-036-cws-1, New York University College of Medicine. March 1, 1944.

4. Werkö, L., The influence of positive pressure breathing on the circulation in man. Acta med. Scandinav., 1947, Supp. 193, 1-125.

5. Motley, H. L., Werkö, L., Cournand, A., and Richards, D. W., Jr., Observations on the clinical use of intermittent positive pressure. J. Aviation Med., 1947, 18, 417.

6. Motley, H. L., Cournand, A., Eckman, M., and Richards, D. W., Jr., Physiological studies on man with the pneumatic balance resuscitator "Burns Model." J. Aviation Med., 1946, 17, 431.

7. Otis, A. B., Rahn, H., Brontman, M., Mullins, L. J., and Fenn, W. O., Ballistocardiographic study of changes in cardiac output due to respiration. J. Clin. Invest., 1946, 25, 413.

8. Fenn, W. O., and Chadwick, L. E., Effect of pressure breathing on blood flow through the finger. Am. J. Physiol., 1947, 151, 270.

9. DeLalla, V., Jr., Causes of skin cooling in pressure breathing, deep inspiration and deep expiration. Am. J. Physiol., 1948, 152, 122.
10. Hyman, C., and Drury, D. R., Changes in pulse velocity during increased intrathoracic pressure. Am. J. Med., 1950, 8, 538.

11. Beecher, H. K., Bennett, H. S., and Bassett, D. L., Circulatory effects of increased pressure in the airway. Anesthesiology, 1943, 4, 612.

12. Watrous, W. G., Davis, F. E., and Anderson, B. M., Manually assisted and controlled respiration. Its use during inhalation anesthesia for the maintenance of a near-normal physiologic state-a review; $\mathrm{Pt}$. II. Anesthesiology, 1950, 11, 661.

13. Orcutt, F. S., and Waters, R. M., A method for the determination of cyclopropane, ethylene, and nitrous oxide in blood with the Van Slyke-Neill manometric apparatus. J. Biol. Chem., 1937, 117, 509.

14. Peterson, L. H., Dripps, R. D., and Risman, G. C., A method for recording the arterial pressure pulse and blood pressure in man. Am. Heart J., 1949, 37, 771.

15. Carr, D. T., and Essex, H. E., Certain effects of positive pressure respiration on the circulatory and respiratory systems. Am. Heart J., 1946, 31, 53.

16. Rushmer, R. F., Circulatory effects of three modifications of the Valsalva experiment; experimental survey. Am. Heart J., 1947, 34, 399.

17. Hamilton, W. F., Woodbury, R. A., and Harper, H. T., Jr., Arterial, cerebrospinal, and venous pressures in man during cough and strain. Am. J. Physiol., 1944, 141, 42.

18. Christie, R. V., and Meakins, J. C., The intrapleural pressure in congestive heart failure and its clinical significance. J. Clin. Invest., 1934, 13, 323.

19. Sarnoff, S., Hardenbergh, E., and Whittenberger, J. L., Mechanism of the arterial pressure response to the Valsalva test. The basis for its use as an indicator of the intactness of the sympathetic outflow. Am. J. Physiol., 1948, 154, 316.

20. Unpublished observations.

21. Abramson, D. I., Grollman, A. I., and Schwartz, A. L., Influence of cyclopropane upon peripheral blood flow in man. Anesthesiology, 1941, 2, 186.

22. Wilkins, R. W., and Culbertson, J. W., The effects of surgical sympathectomy upon certain vasopressor responses in hypertensive patients. Tr. A. Am. Physicians, 1947, 60, 195.

23. Robbins, B. H., Die Wirkung der Cyclopropananasthesie auf den Blutkreislauf. Langenbecks Arch. f. klin. Chir., 1950, 265, 245.

24. Moe, G. K., Rennick, B. R., Freyburger, W. A., and Malton, S. D., The effect of cyclopropane on cardiac work capacity. Anesthesiology, 1949, 10, 706.

25. Bennett, H. S., Bassett, D. L., and Beecher, H. K., Influence of anesthesia (ether, cyclopropane, sodium evipal) on the circulation under normal and shock conditions. J. Clin. Invest., 1944, 23, 181. 